\title{
Membincang Historiografi Islam Abad Pertengahan
}

\author{
Johan Wahyudhi ${ }^{1}$
}

\begin{abstract}
Abstrak
Islam merupakan agama yang memiliki peradaban tinggi. Hal ini terlihat ketika kita membicarakan perkembangan ilmu pengetahuannya yang begitu menawan. Boleh dikatakan, modernisasi yang kita lihat sekarang ini tentu tidak dapat tergelar tanpa sumbangsih Islam. Bagaimanapun, Islam telah menorehkan tinta emas sebagai agama yang tidak saja menenggelamkan diri dalam ibadah ritualistik melainkan juga turut memperhatikan perkembangan umat manusia. salah satu hal yang menjadi perhatian Islam adalah perkembangan penulisan sejarah. Di abad pertengahan Islam, banyak ditemukan langgam-langgam historiografi yang berbeda dengan masa sebelumnya.
\end{abstract}

Kata kunci: Historiografi, Modernisasi, Abad Pertengahan

\begin{abstract}
Islam is a religion which has a high civilization. it is can be seen when we talk about its developing knowledge. Hence, it can be said that modernization, as we see now day, is cannot be standing without the work of Islam. However, Islam had painted a masterpiece as a religion that is not only sinking itself in aspects of ritualistic but it also has a responsibility to fulfill the mankind's need. One of them is the emerging of historiography. In the Islamic middle ages, there are many styles of historiographies which are different from previous era.
\end{abstract}

Keywords: Historiography, Modernization, The Middle Ages.

\footnotetext{
${ }^{1}$ Fakultas Adab dan Humaniora, Universitas Islam Negeri Syarif Hidayatullah Jakarta
} 


\section{A. Pendahuluan}

Historiografi Islam merupakan ranah kajian menarik untuk dikupas. Hal tersebut tidak terlepas dari pergulatannya dengan realitas sosial yang meliputinya. Perannya sebagai suatu diskursus yang menelaah pelbagai langgam bentuk tulisan dan pembabaran kisah-kisah sejarah masa lalu, menjadi vital sebagai raison d'etre ketika membincang gerak jalan corak penulisan yang dinamis dan tidak menutup kemungkinan estetis.

Ketika bandul waktu berarak menuju Abad Pertengahan Islam sekitar tahun 1250-1800, pelbagai ledakan besar peristiwa yang ditetakkan oleh umat manusia menandakan pergulatan zaman yang kian massif dan modern. Pun, dengan wilayah historiografi yang semakin dewasa menembus lorong waktu yang ditandai dengan beberapa pembaruan dan perom-bakan dalam segi penulisannya. Hal ini tidak terlepas dari jerajak zaman yang ikut mempengaruhi peta pemikiran para sejarawan muslim kala itu.

Tak ayal, tradisi penulisan sejarah menjadi satu bentuk dari timbunan produk peradaban yang akan selalu "siap saji" untuk ditelaah. Hasil panenan dari ladangladang kisah Orang Besar yang bermastautin (bertempat) di setiap lembarnya ibarat jalin jemalin benang yang dipintal menjadi mahakarya kain tak terkira eloknya bahkan hingga membentang jauh ke pelbagai ceruk peradaban. Beragam sentuhan-sentuhan magis para pembangun peradaban itu berbalut-erat di kitab-kitab sejarah yang dipahat dalam putihnya kertas sang sejarawan. Historiografi menyu-guhkan pelbagai langgam penulisan terbarukan di zamannya.

Tulisan ini akan mengetegahkan kajian tentang historiografi Islam pada kurun abad pertengahan Islam. Sejarawan Islam kala itu semakin sofistikatif dengan mengetengahkan bentuk-bentuk penulisan yang kian segar dan variatif. Rihlah, merupakan salah stau moda tulisan yang mencuat dalam era ini, Karena penyajiannya yang natural dan lekat sekali dengan rasa penulisnya ketika berdialog dengan keadaan-keadaan sekitarnya.

\section{B. Pembahasan Seputar Abad Pertengahan}

Harun Nasution membagi pembabakan sejarah Islam menjadi tiga era; masa klasik (650-1250), pertengahan (12501800) dan modern (1800-sekarang). ${ }^{2}$ Pendapat lain dilontarkan Jonathan Barkey yang menyebut abad pertengahan Islam (Islamic medieval ages) berkisar antara tahun 1000-1500. ${ }^{3}$ Dua pembagian ini cukup mewakili jalan tengah atau juga landasan berpikir kritis bagi kalangan sejarawan pada umumnya. Pandangan tersebut agaknya cukup membuka wawasan perihal sekat waktu bagi roda perjalanan umat Islam.

Di Era Pertengahan muncul pelbagai peristiwa besar yang ikut serta merubah tatanan dan segi sosial umat Islam. Kurun yang semakin terpisah jauh dari era kenabian membuat tafsir akan kepemimpinan dunia Islam menjadi beragam. Posisi khalifah bukan hanya hidup pada otoritas sosio-keagamaan, namun juga mulai bergeser ke ranah politik. Pada era ini, kutub kummatan terpecah menjadi tiga bagian yakni; Abbasiyah (750-1258 M), Umayyah Andalusia (929-1031 M), dan Fathimiyah (909-1171 M). ${ }^{4}$

Semakin tersebarnya umat Islam ikut pula menggerakkan bahtera peradaban ke masa-masa keemasan. Baghdad bukan saja menjadi pusat pemerintahan di dunia Islam melainkan telah menjelma menjadi kota besar yang kosmopolit. Pelbagai manusia dari belahan manapun datang ke Baghdad dan ikut menghirup angin-angin

\footnotetext{
${ }^{2}$ Harun Nasution, Pembaharuan dalam Islam: Sejarah Pemikiran dan Gerakan (Jakarta: Bulan Bintang, 1982) hlm. 12-14.

3 Jonathan Barkey, The Formation of Islam; Religion and Society in Near East 600 - 1800, (New York: Cambridge University Press, 2003) hlm. 177.

${ }^{4}$ Philip K. Hitti, History of Arab, Terj. Cecep Lukman Hakim, (Jakarta: Serambi, 2008) hlm. 229
} 
progresifitas yang bebas. Tak bisa dipungkiri, Abbasiyah memainkan peran kunci dalam pengorganisasian pelbagai tradisi yang menjadi trend setter di zamannya. Kondisi kota yang inklusif menjadi tengara betapa iklim toleransi dan kebebasan bergaul antarbudaya semakin terjaga sehingga melahirkan produkproduk peradaban yang mutakhir pada zamanya. $^{5}$

Baghdad sejatinya merupakan kota tua yang menjadi salah satu kota satelit di zaman Sasaniyah. Tulang punggung kota ini, yang disebut Richard Fletcher sebagai Round City, dibangun antara tahun 762766. Kendati pada awalnya dibangun mengikuti langgam Persia, begitu Abbasiyah masuk, arsitekturnya mengalami perombakan dan disesuaikan dengan kemegahan khas Abbasiyah dan Islam. Di bagian tengahnya menjulang sebuah menara masjid nan megah dan bangun. Konon, arsitekturnya dibangun dengan teliti, seteliti pembangunan sebuah istana yang dikelilingi taman-taman segar yang menyemburatkan berbagai mozaik aneka warna.

Yang tak kalah mengejutkan, adalah posisi Baghdad yang merupakan cradle of civilization. Dari rahimnya lahir peradaban besar seperti Mesopotamia dan Persia, yang menjadi tulang punggung penyokong kejayaan Islam di tanah tersebut. Alih-alih ditinggalkan, unsur-unsur Persia kerap digunakan dalam proses birokrasi dan tata kelola kerajaan Abbasiyah dimana teokrasi absolut menjadi tradisi yang terus dilanggengkan. Guna efisiensi manajemen kepemerintahan, khalifah tak ragu untuk menunjuk keluarga Barmaki, keluarga yang dipandang sebagai profesor ketatanegaraan Persia, untuk mengatur hal ihwal penyelenggaraan kerajaan. ${ }^{6} \mathrm{Hal}$ ini menjadi cetak biru yang sangat

\footnotetext{
${ }^{5}$ A. Hasjmy, Sejarah Kebudayaan Islam, (Jakarta; Bulan Bintang, 1987) hlm. 251-261 Dan 330-332

6 Richard Fletcher, Relasi damai Islam dan Kristen, Terj. Abdul Malik, (Tangerang Selatan, Alvabet, 2009) hlm. 35.
}

menentukan di mana nepotisme arabistik mulai mengendur dan lebih mengutamakan profesionalitas. ${ }^{7}$

Sebuah penggal kisah menarik ikut pula ditorehkan ketika mengetahui Abbasiyah era Harun as-Rasyid begitu disanjung oleh peradaban barat sebagai raja besar dunia Timur. Adalah Charlemagne , Raja kekaisaran Romawi Suci Prancis menjalin hubungan yang akrab dengan sultan Baghdad. Sebagai bentuk penghargaan sang sultan sempat memberikan patung gajah bernama Abu al-Abbas kepada raja Prancis itu pada tahun 800 M. Gajah sendiri merupakan simbol kebesaran dan keagungan selama beberapa abad. Kendati berbeda tardisi dan agama, tak lantas membuat hubungan kedua raja saling bermusuhan justru yang tercipta adalah merebaknya iklim filatropis yang mengawinkan Timur dan Barat. ${ }^{8}$

Pasca menyurutnya kekuasaan leluhurnya di Damaskus, tak lantas membuat cita-cita Abdurrahman berjuluk "the Falcon of Quraysh", cucu dari Hisyam, khalifah terakhir Dinasti Umayyah berpikir keras untuk memugar kembali kejayaan karya agung leluhurnya. Muawwiyah bin Abi Sufyan. Setelah mengadakan kontemplasi mendalam juga didorong oleh pengejaran tanpa henti dari orang-orang Abbasiyah, Sang Elang memutuskan untuk berlayar ke Andalusia. Di negeri itu, dengan cepat ia mendapatkan kepercayaan dari para pemuka lokal dan diangkat menjadi emir. Tanpa membuang waktu, ia mengorganisasikan pasukan muslim yang kuat dan langsung mengadakan serangkaian pertempuran dengan orang

\footnotetext{
${ }^{7}$ Kendati bangsa Arab mendiami sebagian besar jazirah Arab dan beberapa wilayah di Iraq, namun menilik peta politik pada abad ke $6 \mathrm{M}$, Arab berada pada pengaruh Romawi sedangkan Baghdad pra-Islam masih berada di bawah kekuasaan Persia. Lihat Mahmud Rashid Khatab, Qadah fath al-Iraq wa al-Jazirah (Kairo: Dar al-Qalam, tanpa tahun) hlm. 14

${ }^{8}$ Ibid. hlm, 56
} 
Kristen sejak 756 sampai $788 .{ }^{9}$ Dalam masa itulah namanya semakin disanjung sebagai Sang Pendobrak sehingga dibelakang namanya tersemat gelar $a d$ Dakhil.

Laiknya Baghdad, Cordova yang menjadi pusat pemerintahan Islam di Andalusia, disulap menjadi kota yang molek lagi modern di zamannya. Sebenarnya, Cordova adalah kota lama yang direkonstruksi kembali dengan model kota yang astistik penuh dengan gaya Islam. Menurut catatan Jurzi Zaidan, bangunan yang terdapat dalam kota ini terdiri atas; 1) 113.000 rumah rakyat; 2) 430 istana besar dan kecil; 3) 6. 300 rumah pegawai negeri; 4) 3. 873 masjid; 5) 900 tempat pemandian (hamamaat); 6) 8. 455 toko besar dan kecil. ${ }^{10}$

Islam di Spanyol (Andalusia)
menyumbangkan peradaban berupa perbendaharaan ilmu yang tak berbilang banyaknya. Selain Cordova yang terkenal dengan kemegahan fisik kotanya, Toledo menjadi destinasi keilmuan yang menjadi "pangeran ilmu" yang mencerahkan Eropa. Dari Toledo, pelbagai risalah-risalah filsafat membanjiri biara-biara yang menjadi otoritas ketuhanan dan kebenaran yang absah di mata penduduk Eropa. Para uskup dan bruder rajin mengkaji teks-teks Aristoteles dan Plato dalam "bahasa padang pasir". Suatu peristiwa yang kerapkali lekang dalam historiografi Barat. ${ }^{11}$

Fathimiyah menjadi kiblat keislaman yang tidak boleh tertinggal ketika membentangkan wacana Islam abad pertengahan yang merekah indah. Kairo yang menjadi ibukotanya merupakan salah satu kota yang paling termashur di kala itu. sebagaimana diketahui, Kairo atau Mesir pada umumya, adalah world great

\footnotetext{
9 Carl Brockelmann, History of The Islamic Peoples, (London: Routledge \& Kegan Paul Limited, 1949) hlm. 181-182.

10 Hasjmy, Sejarah Kebudayaan, op. cit, hlm. 202.

11 Tamim Ansary, Dari Puncak Bagdad; Sejarah Dunia Versi Islam, (Jakarta: Zaman, 2010) hlm. 332-333.
}

legacy dari kemaharajaan Mesir Pharaoh yang sempat memimpin peradaban umat manusia beratus-ratus tahun sebelum masehi. Masa keemasan Mesir dimulai sejak revolusi pribumi melawan kaisar Hykos yang desotik pada tahun 1700 SM sampai kapturisasi atas negeri itu oleh bangsa Romawi pada tahun $39 \mathrm{M}^{12}$ Keduukannya sebagai umm al-dunya, ${ }^{13}$ ini tak bisa dilepaskan dari pelbagai masterpiece yang dirorehkannya bagi akselerasi pertumbuhan modernitas hingga mencapai abad serba "E"14 atau dunia internet seperti saat ini.

Yang menjadi sorotan labih dalam, adalah peran Mesir sebagai oase peradaban manusia kuno yang masih dijaga oleh umat Islam. Di zaman Fathimiyah dibangun sebuah universitas yang hingga kini masih berdiri tegak yang bernama al-Azhar. Setali tiga uang dengan pembangunan gedung pendidikan itu, Kairo terangkat pula ke panggung dunia sebagai menara keilmuan yang berkilau di utara Afrika menyemburat ke seluruh dunia. Fusthath dan Iskandariyah, sebagai tempat bersemayamnya pebagai keilmuan, juga menyokong keanggunan perbendaharaan pengetahuan Kairo selama berabad-abad. ${ }^{15}$

Kondisi sosio-intelektual yang semakin mapan dikembangbiakkan oleh kutub-kutub kekuasaan Islam pada abad pertengahan turut menggairahkan keinginan para sejarawan untuk menulis sejarah. Di abad pertengahan sendiri, semesta historiografi telah mencapai tahap maturitas yang bukah hanya dewasa melainkan juga elegan.

12 Hendrik Willem van Loon, The Story of Mankind, ( USA: Boni and Liveright, 1922) Cet. 12, hlm. 27-28.

13 Zuhairi Misrawi, Al-Azhar; Menara Ilmu, Reformasi, dan Kiblat Keulamaan, (Jakarta: Gramedia, 2010) h. 44

14 Thomas L. Friedman, The Lexus and The Olive Three, (New York: Anchor Books, 2000) hlm. 73 .

15 Hasjmy, Sejarah Kebudayaan, op. cit, hlm. 264. 


\section{Perkembangan Langam Historiografi}

Pada Era Pertengahan, terjadi beberapa pembaruan dalam corak historiografi Islam. Hal ini tak terlepas dengan keadaan agama ini yang semakin diterima oleh penganut lain, menembus batas angin gurun khas Hijaz dan mulai bermastautin di ceruk peradaban dunia seperti Syria dan Persia. Alih-alih tetap berpegang pada gaya klasik yang melulu bertumpu pada tradisi penulisan Arab dan senantiasa kembali ke qur'an dan hadis, masing-masing sejarawan telah memadukan pelbagai kepakarannya dengan unsur-unsur lokal di mana ia berpijak. Kemunculan tiga sungai besar langgam penulisan: Madinah, Yaman, dan Irak $^{16}$ menjadi indikasi betapa kubah pemikiran para historiograf sudah mampu mencerap perbagai kearifan lokal di wilayah setempat, sehingga dapat keluar dengan pendekatan-pendekatan yang baru pada zamannya.

Yusri Abdul Ghani Abdullah mengungkapkan bahwa gerak zaman keberislaman amatlah berakaitkelindan dengan beberapa faktor yang menjadi katalisnya, antara lain:

Pertama, Melimpahruahnya bahanbahan kesejarahan sebagai akibat maraknya pembangunan lembaga-lembaga peme-rintahan pada masa Dinasti Abbasiyah, utamanya lembaga administrasi, kemili-teran, perpajakan, dan pos.

Kedua, Maraknya aktivitas penerjemahan karya-karya dari bahasa Persia, Yunani, Suryani, dan Latin ke dalam bahasa Arab.

$\begin{array}{cr}\text { Ketiga, Ketersediaan } & \text { sarana } \\ \text { mobilitas yang memadai yang }\end{array}$ memanjakan para pelajar dan sejarawan untuk melakukan penjelajahan ilmiah guna mencari riwayat, melihat keajaiban-

16 Badri Yatim, Historiografi Islam (Jakarta: Logos Wacana Ilmu, 1997) hlm. 41- 79. keajaiban di daerah lain serta peninggalan sejarahnya. ${ }^{17}$

Keempat, Eksplosi perdagangan ke dunia Timur Jauh, terutama ke Malaka, sehingga ikut membawa serta rasa ingin tahu yang mendalam akan tradisi dan budaya liyan.

Jika dilihat dari judulnya saja, misalnya seperti Tarikh Baghdad buah tangan Abu Bakar al-Baghdadi sudah mengindikasikan suatu kefokusan atau dalam bahasa lain disebut juga kepakaran akan suatu cakupan wilayah Islam. Hal ini menjadi indikasi betapa langgam tulisan semisal maghazi dan ansab sudah mengalami stagnansi-untuk tidak mengatakan semua-sehingga banyak di kalangan sejarawan sudah mulai meninggalkan pola lama dan beralih pada suatu kajian yang mengupas suatu kisah sejarah secara lebih intim, kendati dalam skup yang lebih kecil, namun terasa lebih mendalam pembahasannya.

Pun dengan tulisan sejarah yang berbentuk traveler notes menjadi varian anyar yang tak kurang hangat disambut di dunia historiografi Islam. Yang paling populer, tentu saja adalah karya Ibnu batutta yang ditulis pada abad ke 15, bahkan ia sempat menuliskan keadaan Pasai yang sempat dikunjunginya pada tahun 1343 dan $1346 .^{18}$

Boleh dikatakan point d'appui dari meluncurnya gaya penulisan yang berisikan heterogenitas pembahasan di luar Arab menemukan momentumnya dengan munculnya karya monumental Abul Abbas al-Baladhuri, sejarawan Muslim klasik pada paruh ketiga hijriyah (sekitar 892 atau $893 \mathrm{M}$ ), dengan masterpiece-nya Futuh al-Buldan yang begitu apik mengisahkan penaklukanpenaklukan di luar Arab. Di volume 2

\footnotetext{
${ }^{17}$ Yusril Abdul Ghani Abdullah, Historiografi Islam; dari Klasik HIngga Modern, ( Jakarta: RajaGrafindo Persada, 2004) hlm. 17.

18 Ross E. Dunn, Petualangan Ibnu Batutta, (Jakarta: Yayasan Obor Indonesia, 2011), Cet. 2, hlm. 289.
} 
misalanya, al-Baladhuri memaparkan bagaimana proses dan hal lain seputar penaklukan Media Utara (Rayy, Kumas, Kazwin, dan Zanjan), Azerbaijan, Mosul (Iraq), Jurjan dan Tabaristan, Tigris, Kurdistan, Fars, Kirman, Sijistan dan Kabul (Asia Tengah), Khurasan (Uzbekistan), dan Sind (India). Penulisan telah bergulir membahas kota-kota terpenting, sebagai acces guide dalam efektifitas penelusuran pelbagai kisah awal terkait penaklukannya. Disajikan per babnya membahas satu atau dua kota. ${ }^{19}$

Selain itu, penulisan biografi juga mengalami kemajuan yang pesat. Paska hancurnya Baghdad oleh Hulagu Khan pada tahun 1258, Abul Khair al-Hamdani, sejarawan Persia sempat menuliskan biografi penguasa pastoral dari Asia Tengah itu. Bagaimanapun, hancurnya Baghdad merupakan sebuah luka mendalam bagi umat Islam. Namun, sebagai seorang sejarawan terkait posisinya sebagai pewarta zaman tentu saja hal itu bukan merupakan batu sandungan dengan mengabadikan kisah sang penakluk sebagai informasi untuk umat masa depan.

Yang menarik adalah ketika melihat judul-judul kitab yang ditulis oleh Lisauddin as-Salmani, sejarawan dari tlatah Andalusia. Seperti yang terlihat di beberapa karyanya (lihat sub bab c no. 13) yang melulu mengupas tentang Granada, salah satu kota penting dalam peradaban Islam di Semenanjung Iberia kala itu. Sang sejarawan seakan ingin memposisikan dirinya sebagai pakar Granada. Suatu fenomena yang agaknya berulang di masa kini di mana keahlian hanya mencakup dalam satu bidang yang ditekuninya secara mendalam.

Yang tak boleh dan tidak boleh tidak dipaparkan di sini adalah buah karya Ibnu Khaldun berjudul Muqaddimah yang merupakan jilid awal dari kitab al-'Ibar

19 Lebih lanjut lihat al-Baladhuri, Futuh alBuldan, Part 2, trans. by Francis Clark Murgotten (New York: Longman, Greens \& Co., 1924). wa Diwan al-Mubtada' wal Khabar fi Ayyam al-Arab wal Ajam wal Barbar wa Man 'Asaruhum Min Dzawil Sultan alAkhbar - "Contoh-contoh yang mengandung pelajaran dan kumpulan usul-usul dan informasi mengenai sejarah bangsa Arab, Persia, dan Barbar. "Tak bisa dipungkiri, karya ini merupakan karya agung dalam historiografi abad pertengahan. Dalam karya ini, ia menggelar kaidah-kaidah yang dipakainya dalam meneliti sejarah. Ia juga mulai mewartakan akan pentingnya menulis dengan merujuk pada patron kaidah yang bersifat objektif-ilmiah, baik dalam pengamatan, pengumuman, dan pegujian fakta-fakta, maupun dalam menyintesakannya dengan pisau logika induktif. Sejarah tidak boleh hanya mengorbit pada penyampaian kisah yang rasional maupun tidak atau dengan metode spekulatif metafiskal. Dengan demikian, ia menjadi konseptor pertama dalam historiografi modern. ${ }^{20}$

Merujuk pada terjemahan versi Frank Rosenthal, Muqaddimah terbagi atas 6 bab, yakni:

\section{Human civilization in general}

2. Bedouin civilization, savage nations and tribes and their conditions of life, including several basic and explanatory statements.

3. On dynasties, royal authority, the caliphate, governments rank, and all that goes with this things. The chapter contains basic and supplementary propositions.

4. Countries and cities, and all other form of sedentary civilization. The conditions occurring there, primary and secondary considerations in this connection.

5. On the various aspects of making a living, such a profit and the crafts. The conditions that occur in this connection. A number of problems are connected with this subject.

${ }^{20}$ S. I. Poeradisastra, Sumbangan Islam kepada Ilmu dan Peradaban Modern, (Depok, Komunitas Bambu, 2008), Cet. 3, hlm. 68-69. 
6. The various kinds of sciences, the methods of instruction, the conditions that obtain in these connections. The chapter includes a prefatory discussion and appendicies. $^{21}$

Bisa diperhatikan lebih lanjut, betapa pembagian bab telah mengalami dinamika yang pesat tinimbang masa sebelumnya. Di bab 6, sebagaimana telah disinggung sebelumnya, Ibnu Khaldun menyampaikan pula metodologi "menangkap" kebenaran melalui serangkum penelitian yang bersifat empiris, seperti yang dikatakannya:

The concepts bringing this about are not completely divorced from sensual perception and do not require very deep study. All of them are obtained through experience and derived from it. They are particular concepts connected with the sensibilia. Their truth or falsehood soon comes out in events. From (events) the student of these concepts can learn them. Each human being can learn as much of them as he is able to. He can pick up (his knowledge) with the help of experience among the events that occur in his dealings with his fellow men. Eventually, he will have what is necessary and must be done, and must not be done, fixed in his(mind). By knowing this well, then, the proper habit of dealing with his fellowmen will be obtained by him. ${ }^{22}$

Agaknya, apa yang dituangkan dalam pembahasan Ibnu Khaldun di atas telah cukup mewakili historiografi yang meng-gunakan pisau analisa dari pelbagai ilmu sosial. Terkait hal ini, Aziz al-Azmeh mengungkapkan:

\section{Constructivism in historical scholarship allows for the proper constitution of objects of study- population movements, economic cycles, social relations, ideologies, mentalities,}

21 Ibnu Khaldun, The Muqaddimah, trans. by Frank Rosenthal (tp.p, tanpa tahun)

${ }^{22}$ Ibid, hlm. 549. and so forth. The exposition of historical topics deliberately constituted might be and is indeed often narrative, and therefore subject to the structures of all narrative. But scientific historical writing also needs to go beyond story-telling, and involve analytical procedures derived from a variety of social science disciplines. Of the objects of historical study are the subcategories of an historical mass: a nation, a community, a civilization. A certain, pervasive, vitalism and organismic notion of historical mass implies notions of time and temporality which reclaim, implicitly or explicitly, duration at the expense of chronometry, and it is this which will be investigated in the first section of this essay, before the discussion is widened to certain tropes of Arabic and Muslim historical writing. ${ }^{23}$

\section{Beberapa Sejarawan dan Karyanya}

1. Al- Amid, (1) Jirjis al-Makim Abdullah ibnu Abil Yasir ibnu Abil Makarim, (2) Tahun 1205 atau 1206 hingga 1273 atau 1274, (3) Mesir, (4) ?, (5) Historiografi, (6) Kitab alMajmu' al-Mubarak- kumpulan orang-orang yang diberkati, sejarah Muslim.

2. Al-Andalusi, (1) Abul Qasim Sa'id ibnu Ahmad ibnu Abdul Rahman ibnu Muhammad ibnu Sa'id al-Qurtubi, juga disebut Qadi Sa'id, (2) Tahun 1029 atau 1030 hingga 1070, (3) Spanyol, (4) ?, (5) Historiografi, (6) Kitab at-Ta'rif bu Thabaqat al-Umam - ikhtisar sejarah dunia; sejarah para ilmuwan.

3. Al-Baghdadi, (1) Abu Bakr Ahmad ibnu Ali ibnu Tsabit al-Khatib, (2) tahun 1002-1071, (3) ?, (4) ?, (5) Historiografi, (6) Tarikh Baghdad Sejarah para ilmuwan Baghdad, 14 volume; Kitab al-Kifayah fi Ma'rifat

\footnotetext{
23 Aziz al-Azmeh, The Times of History; Universal Topics in Islamic Historiography (Budapest: Central European University Press, 2007) hlm. 5.
} 
Ushul 'Ilm ar-Riwayah - Risalah tentang kritik terhadap tradisi, dan lain-lain.

4. Al-Banakati, (1) Fakhruddin Abu Sulaiman Da'ul Ibnu Muhammad, (2) wafat tahun 1329 atau 1330, (3) Persia, (4) Bahasa Persia, (5) Historiografi, (6) Raudhatul Albab fi Tawarikh al-Akabir wal Ansab Taman orang-orang besar dan tentang silsilahnya.

5. Ibnu Futi, (1) Kamaluddin Abul Fada'il Abdurrazaq ibnu Ahmad ibnu Muhammad,(2) Tahun 1244-1323, (3) Irak, (4) Bahasa Arab, (5) Historiografi, (6) Al-Hawadits alJami'a wal Tajarib an-Nafi'a Min alMi'a al-Sabi'a - berhubungan dengan khalifah Abbasiyah terakhir dan permulaan dominasi Mongol hingga tahun 1300; Majma't al-Adab fi Mu'jam al-Asma' wa Alqab - Kamus biografis; Mukhtasar Akhbar alKhulafa' al-Abbasiyyin - Kumpulan cerita mengenai khalifah Abbasiyah; serta banyak lagi karya yang berhubungan dengan sejarah dan filologi, seluruhnya hilang.

6. Al-Hamdani, (1) Abul Khair Rasyiduddin Fadlillah Ibnu 'Imad adDawla (sering disebut Rasyiduddin Tabib), (2) tahun 1247-1318, (3) Persia, (4) Bahasa Persia, Arab (5) Historiografi, (6) Jami' at-Tawarikh kumpulan sejarah; Biografi Hulagu Khan.

7. Ibnu Hammad, (1) Abu Abdullah Muhammad Ibnu Ali, (2) Tahun 1150-1230, (3) Bu-Hamra, (4) ?, (5) Historiografi, (6) Akbar Muluk Bauk Ubaid Wa Siratutum - CatatAn tentang penguasa Fathimiyah di Afrika; Tarikh tentang Bougie (Bijaya).

8. Al-Isfahani, (1) Muhammad ibnu Muhammad Imaduddin al-Katib, (2) Tahun 1125-1201, (3) Persia, (4) Bahasa Arab, (5) Historiografi, (6) Kitab al-Fath al-Qussi - Sejarah tentang penaklukan Syria oleh
Saladin; Kitab al-Barqash- Sha'mi (Shami' ?) - Laporan ilmiah berhubungan dengan sejarah.

9. Al-Jaziri, (1) Abul Hasan Ali ibnu Muhammad 'Izzuddin ibnul Atsir asy-Syaibani (lebih dikenal dengan Ibnu Atsir), (2) Tahun 1160-1233, (4) Mesopotamia, (4) ?, (5) Historiografi, (6) Kitab al-Kamil fil Tarikh - Buku yang sempurna tentang tarikh; Sejarah tentang para penguasa Atabeg dari Mosul (1127-1211).

10. Ibnu Batutah, (1) Abu Abdullah Muhammad ibnu Abdullah ibnu Muhammad al-Lawati al-Hanji, (2) Tahun 1304-1377 atau 1378, (3) Tangiers, (4) ?, (5) Geografi, (6) Tuhfat a-Nuzzar fi Qara'ib al-Amshar wa Aja'ib al-Asfar- Hadiah bagi para peneliti berhubungan dengan orangorang yang ingin tahu terhadap kotakota dan perjalanan yang menakjubkan.

11. Ibnu Khaldun, (1) Abdul Rahman ibnu Khaldun, (2) Tahun 1333-1406. (3) Tunisia, (4) ?, (5) Historiografi, (6) Muqaddimah - pengantar untuk daftar berikut; Kitab al-'Ibar wa Diwan al-Mubtada' wal Khabar fi Ayyam al-Arab wal Ajam wal Barbar wa Man 'Asaruhum Min Dzawil Sultan al-Akhbar - "Contoh-contoh yang mengandung pelajaran dan kumpulan usul-usul dan informasi mengenai sejarah bangsa Arab, Persia, dan Barbar."

12. Al-Marrakusyi, (1) Abu Muhammad Abdul Wahid ibnu Ali atTamimi al-Marrakusyi Muhyiddin, (2) tahun 1185-1224, atau wafat lebih belakang, (3) Marrakusy, (4) ?, (5) Historiografi,(6) Kitab al-Mu'jib fi Talkhis Akhbar Ahl al-Maghrib Sejarah rakyat Afrika.

13. As-Salmani, (1) Lisanuddin Abu Abdullah Muhammad ibnu Abdullah, (2) Tahun 1313-1374, (3) MuslimHispano, (4) ?, (5) Historiografi, (6) al-Hulal al-Marquma - "Sejarah para Khalifah Timur dan Barat" ; A'mal 
al-A'lam - Sejarah Muslim Timur dan Barat ; Al-Lamhah al-Badriyya fil Dawla an-Nasiriyya - Sejarah Granada hingga tahun 1363; AlIhathah bi Tarikh Qarnata Kumpulan mengenai sejarah Granada; At-Taj al-Muhalla - Sejarah Spanyol sejak tahun 1232; Mi'yar al-Ikhtiyar; Mufakharat Malaqa wa Sala Persaingan antara Malaga dan Sala; Al-Hulal Al-Maushiyya fi Dzikr alAkhbar al-Marrakushiyya - Tarikh tentang Maroko; Nufadat al-Jirab fi Ulalat al-Ightirab - buku kenangkenangan Maroko; Khatrat at-Taif fi Rihlat ash-Shita wal Saif - Perjalanan di Granada Timur; Manfa'at as-Sa'il an al-Marad al-Ha'il - Catatan wabah penyakit yang terjadi di Granada tahun 1348.

14. Asy-Syafi'i (1) Abul Qasim Ali ibnu Abi Muhammad al-Hasan ibnu Hibatullah Tsiqatuddin ibnu 'Asakir asy-Syafi' I, (2) tahun 1105-1175, (3) Damaskur, (4) ?, (5) Sejarawan dan tradisionis Muslim, (6) Tarikh Madinat Dimashqi - Sejarah kota Damaskus, 80 volume.

15. As-Subkhi, (1) Tajuddin Abu Nasr Abdul Wahhab ibnu Ali, (2) Tahun 1327-1370, (3) Mesir, (4) ?, (5) Historiografi, (6) Thabaqat asySyafi'iyyah - Biografi para ahli teologi Syafi'iyyah.

16. Ibnu Wasil, (1) Abu Abdullah Muhammad ibnu Salim ibnu Wasil Jamaluddin, (2) Tahun 1207 atau 1208-1298, (3) ?, (4) ?, (5) Dokter, Sejarawan, Filosof, ahli Matematika, (6) Kitab Mufarrijj al-Kurub fi Akhbar Bani Ayyub - "Buku yang menghilangkan kesedihan dengan hikayat-hikayat al-Ayyub.

17. Al- Yamani, (1) Abu Muhammad Umara ibnu Ali ibnu Zaidan alYamani Najamuddin, (2) Tahun 1121 atau 1122-1174, (3) Yaman, (4) ?, (5) Ahli Sejarah Muslim, (6) Tarikh Yaman - Sejarah Yaman; Qasa'id Otobiografi; Kitab an-Nukat al-
'Asriyya fi Akhbar al-Wuzara' alMisriyya - seluk beluk kontemporer mengenai para menteri dari Mesir. ${ }^{24}$

\section{Penutup}

Abad Pertengahan besar meletupkan ledakan besar dalam rancang bangun historiografi Islam. Meluasnya ajaran Muhammad ke lekuk-lekuk dunia nun jauh dari tanah kelahirannya, Hijaz, semakin mengumandangkan bahwa dunia baru penulisan sejarah Muslim telah dimulai.

Karya-karya sejarah deras mengalir dari ceruk tiga menara peradaban Islam yakni; Baghdad, Cordova, dan Kairo. Rebut tengkar klaim kekhalifahan berimbas apik bagi lelaju dinamis jejak rekam penulisan sejarah. Dari yang tadinya bersifat Arabistik dan sukuisme khas kaum Badui mulai merekah menyemburatkan kosmopoli-tanisme langam penulisan serta terma-terma yang diangkat dalam suatu babaran sejarah.

Abad ini boleh dikatakan era dimana pintu gerbang pacu kuda-kuda peradaban Islam mulai dibuka dan berlari melintas aral batas laut dan pegunungan. Hal ini ikut pula membawa ngin surga bagi tradisi historiografi Islam. Gaya uraian atas kajian studi yang lebih mendalam, diwujudkan dengan adanya beberapa karya yang sifatnya tematik dan tak sedikit yang berlandaskan pada catatan-catatan per-jalanan ke negeri asing. Pun dengan pisau analisa dari ilmu-ilmu sosial, sudah mulai menunjukkan geliatnya dan dipakai dalam membelah pelbagai kisah dan tafsir sejarah.

\footnotetext{
24 Mehdi Nakosteen, Kontribusi Islam atas Dunia Intelektual Barat, Terj. Joko S. Kahhar (Surabaya: Risalah Gusti, 2003) hlm. 336-354.
} 


\section{Daftar Pustaka}

Abdullah, Yusril Abdul Ghani, Historiografi Islam; dari Klasik HIngga Modern, ( Jakarta: RajaGrafindo Persada, 2004). al-Baladhuri, Abul Abbas, Futuh al-Buldan, Part 2, trans. by Francis Clark Murgotten (New York: Longman, Greens \& Co., 1924).

al-Azmeh, Aziz, The Times of History; Universal Topics in Islamic Historiography (Budapest: Central European University Press, 2007).

Ansary, Tamim, Dari Puncak Bagdad; Sejarah Dunia Versi Islam, (Jakarta: Zaman, 2010).

Barkey, Jonathan, The Formation of Islam; Religion and Society in Near East 600 - 1800, (New York: Cambridge University Press, 2003).

Brockelmann, Carl, History of The Islamic Peoples, (London: Routledge \& Kegan Paul Limited, 1949).

Dunn, Ross E., Petualangan Ibnu Batutta, (Jakarta: Yayasan Obor Indonesia, 2011).

Fletcher, Richard, Relasi damai Islam dan Kristen, Terj. Abdul Malik, (Tangerang Selatan, Alvabet, 2009).

Friedman, Thomas L., The Lexus and The Olive Three, (New York: Anchor Books, 2000).

Hasjmy, A., Sejarah Kebudayaan Islam, (Jakarta; Bulan Bintang, 1987).

Hitti, Philip K., History of Arab, Terj. Cecep Lukman Hakim, (Jakarta: Serambi, 2008).

Khaldun, Ibnu, The Muqaddimah, trans. by Frank Rosenthal (tp.p, tanpa tahun).

Khatab, Mahmud Rashid, Qadah fath al-Iraq wa al-Jazirah (Kairo: Dar al-Qalam, tanpa tahun).

Loon, Hendrik Willem van, The Story of Mankind, ( USA: Boni and Liveright, 1922).

Misrawi, Zuhairi, Al-Azhar; Menara Ilmu, Reformasi, dan Kiblat Keulamaan, (Jakarta: Gramedia, 2010).
Nakosteen, Mehdi, Kontribusi Islam atas Dunia Intelektual Barat, Terj. Joko S. Kahhar (Surabaya: Risalah Gusti, 2003).

Nasution, Harun, Pembaharuan dalam Islam: Sejarah Pemikiran dan Gerakan (Jakarta: Bulan Bintang, 1982).

Poeradisastra, S. I., Sumbangan Islam kepada Ilmu dan Peradaban Modern, (Depok, Komunitas Bambu, 2008).

Yatim, Badri, Historiografi Islam (Jakarta: Logos Wacana Ilmu, 1997). 